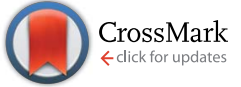

Cite this: RSC Adv., 2017, 7, 3265
Received 3rd October 2016 Accepted 28th November 2016

DOI: $10.1039 / c 6 r a 24699 k$

www.rsc.org/advances

\section{Carbon molecular sieve membrane from a microporous spirobisindane-based polyimide precursor with enhanced ethylene/ethane mixed- gas selectivity $\dagger$}

\begin{abstract}
Octavio Salinas, Xiaohua Ma, Yingge Wang, Yu Han and Ingo Pinnau*
Ethylene is typically produced by steam cracking of various hydrocarbon feedstocks. The gaseous products are then separated in a demethanizer followed by a deethanizer unit and finally sent to a $C_{2}$ splitter for the final purification step. Cryogenic distillation of ethylene from ethane is the most energy-intensive unit operation process in the chemical industry. Therefore, the development of more energy-efficient processes for ethylene purification is highly desirable. Membrane-based separation has been proposed as an alternative option for replacement or debottlenecking of $C_{2}$ splitters but current polymer membrane materials exhibit insufficient mixed-gas $\mathrm{C}_{2} \mathrm{H}_{4} / \mathrm{C}_{2} \mathrm{H}_{6}$ selectivity $(<7)$ to be technically and economically attractive. In this work, a highly selective carbon molecular sieve (CMS) membrane derived from a novel spirobisindane-based polyimide of intrinsic microporosity (PIM-6FDA) was developed and characterized. PIM-6FDA showed a single-stage degradation process under an inert nitrogen atmosphere which commenced at $\sim 480{ }^{\circ} \mathrm{C}$. The CMS formed by pyrolysis at $800{ }^{\circ} \mathrm{C}$ had a diffusion/ size-sieving-controlled morphology with a mixed-gas $\left(50 \% \mathrm{C}_{2} \mathrm{H}_{4} / 50 \% \mathrm{C}_{2} \mathrm{H}_{6}\right)$ ethylene/ethane selectivity of 15.6 at 20 bar feed pressure at $35{ }^{\circ} \mathrm{C}$. The mixed-gas ethylene/ethane selectivity is the highest reported value for CMS-type membranes to date.
\end{abstract}

\section{Introduction}

Ethylene $\left(\mathrm{C}_{2} \mathrm{H}_{4}\right)$ is produced in larger quantity than any other organic compound with a world-wide production of 141 million tons in $2011 .^{1}$ Most commonly, $\mathrm{C}_{2} \mathrm{H}_{4}$ is produced by steam cracking of hydrocarbon-based feedstock, such as naphtha, ethane etc., which is the most energy-intensive process in the chemical process industry. After cracking, hydrogen and methane are first removed in a demethanizer unit and the dried hydrocarbon feed is then sent to a deethanizer to split the $\mathrm{C}_{2}$ from $\mathrm{C}_{3+}$ hydrocarbons. In the final process step, ethylene and ethane are separated in a highly energy-intensive cryogenic distillation $\mathrm{C}_{2}$ splitter. The required distillation columns operate typically at $20 \mathrm{bar}$ and $\sim-20^{\circ} \mathrm{C}$, are often more than $100 \mathrm{~m}$ tall and contain over 200 trays. The total world energy consumption for ethylene production was about 2-3 EJ (1 EJ = $1 \times 10^{18} \mathrm{~J}$ ) in $2004 .^{1}$ Therefore, alternative unit operation processes, such as membrane technology, which may require

King Abdullah University of Science and Technology (KAUST), Advanced Membranes and Porous Materials Center (AMPMC), Physical Sciences and Engineering Division, Chemical and Biological Engineering Program, Thuwal 23955-6900, Saudi Arabia. E-mail: ingo.pinnau@kaust.edu.sa

$\dagger$ Electronic supplementary information (ESI) available: Raman and FTIR spectra; densities; ethylene and ethane sorption isotherms; dual-mode and Langmuir parameters. See DOI: 10.1039/c6ra24699k less energy input for efficient ethylene/ethane separation, are highly desirable. ${ }^{2}$ Recent process modeling suggested that a membrane/distillation hybrid process to debottleneck ethylene/ ethane distillation units could potentially save energy, ${ }^{3-5}$ provided that a membrane material has high ethylene/ethane selectivity of $\geq 10$ and withstands realistic process conditions., ${ }^{\mathbf{4}, 6}$

Currently available commercial membrane materials used for gas separation applications mainly comprise low-freevolume, solution-processable, glassy polymers, which exhibit an inverse relationship between permeability and selectivity. ${ }^{7}$ In 2002, Fuertes and Menendez reported a permeability/selectivity trade-off relationship for the ethylene/ethane system, ${ }^{8}$ which was updated in 2013 by Rungta et al. ${ }^{9}$ So far, the best performing polymers are polyimides that offer pure-gas ethylene/ethane selectivities of up to $\sim 7$ when tested at low feed pressures. ${ }^{\mathbf{1 0 - 1 3}}$ Under high pressure mixed-gas conditions (i.e. high hydrocarbon activity) penetrant-induced plasticization and competitive sorption typically cause even lower selectivity. ${ }^{11}$ Recently, mixed-matrix membranes containing polyimides with various metal-organic frameworks were reported to increase the ethylene permeability and/or ethylene/ethane selectivity. Ploegmakers et al. demonstrated that addition of $20 \mathrm{wt} \%$ $\mathrm{Cu}_{3} \mathrm{BTC}_{2}$ to $\mathrm{P} 84 \AA$ polyimide increased the pure-gas selectivity from 4.1 for the pristine polymer to 7.1 for the mixed-matrix membrane. However, the ethylene permeability of 0.051 
Barrer $\left(1\right.$ Barrer $=1 \times 10^{-10} \mathrm{~cm}^{3}(\mathrm{STP}) \mathrm{cm} \mathrm{cm}^{-2} \mathrm{~s}^{-1} \mathrm{cmHg}^{-1}$ ) was extremely low. ${ }^{14}$ Bachman et al. reported highly permeable mixed-matrix membranes for ethylene/ethane separation based on 6FDA $\left(4,4^{\prime}\right.$-(hexafluoroisopropylidene)diphthalic anhydride)-DAM (2,4,6-trimethyl-1,3-phenylenediamine) polyimide blended with $\mathbf{M}_{2}$ (dobdc) metal-organic framework nanocrystals (dobdc ${ }^{4-}=2,5$-dioxido-1,4-benzenedicarboxylate). ${ }^{15}$ A 6 FDA-DAM membrane containing $25 \%$ $\mathrm{Ni}_{2}$ (dobdc) demonstrated excellent ethylene permeability of 268 Barrer when tested under mixed-gas conditions with an equimolar ethylene/ethane mixture at 20 bar feed pressure. However, the high permeability was coupled with an ethylene/ ethane selectivity of only 4.1 .

Ultramicroporous carbon molecular sieve (CMS) membranes derived from polyimide precursors have so far demonstrated the most promising gas separation performance for ethylene/ethane separation. ${ }^{9}$ For example, a CMS membrane made from Matrimid ${ }^{\circledR}$ vacuum-pyrolized at $675{ }^{\circ} \mathrm{C}$ showed excellent mixed-gas permeation properties (feed conditions: $63.2 \% \mathrm{C}_{2} \mathrm{H}_{4} / 36.8 \% \mathrm{C}_{2} \mathrm{H}_{6}$; feed pressure: $3.4 \mathrm{bar}$; permeate pressure: vacuum; $T: 35^{\circ} \mathrm{C}$ ) with a $\mathrm{C}_{2} \mathrm{H}_{4}$ permeability of 10.9 Barrer and $\mathrm{C}_{2} \mathrm{H}_{4} / \mathrm{C}_{2} \mathrm{H}_{6}$ selectivity of 12.3 . Pyrolysis at $800{ }^{\circ} \mathrm{C}$ resulted in a large drop in $\mathrm{C}_{2} \mathrm{H}_{4}$ permeability to only 0.2 Barrer without much effect on selectivity. ${ }^{16} \mathrm{CMS}$ membranes comprise a disordered array of stacked graphene sheets generated from thermally degraded polymeric matrices. ${ }^{\mathbf{1 7}, 18}$ Fundamentally, the formation of size-sieving ultramicropores in CMS membranes is determined by a series of complex reactions (e.g. cyclization, dehydrogenation, crosslinking, and oxidation) during the pyrolysis of the polymer precursor structure. ${ }^{19}$ The evolution of the pore size distribution (PSD) during the pyrolysis protocol is a strong function of the polymer precursor structure itself. ${ }^{20-22}$ Functional groups, such as $-\mathrm{OH},-\mathrm{COOH},-\mathrm{CN}$ etc. can lead to potential reactions during the various stages of the pyrolysis process. In general, heatreactive segments of a polymer chain may create voids left by gas phase evolved molecules ${ }^{23}$ or may form pre-crosslinks that open the CMS structure leading to higher permeability. ${ }^{24}$

Recently, solution-processable polymers of intrinsic microporosity (PIMs) were introduced as potential membrane materials for various gas separation applications. ${ }^{25-31}$ PIMs are characterized by high BET (Brunauer-Teller-Emmett) surface area of up to $\sim 1000 \mathrm{~m}^{2} \mathrm{~g}^{-1}$ with micropores of less than $2 \mathrm{~nm}$. Because of their large free volume and microporous structure, most PIMs are significantly more permeable than low-freevolume glassy polymers, such as polysulfone or cellulose acetate, but have lower selectivity. However, optimized PIMs containing a large fraction of ultramicropores of less than $7 \AA$, can discriminate between gases with small differences in molecular dimensions and some types based on triptyceneand Tröger's base molecular building blocks have defined the 2015 polymeric upper bound performance for air and hydrogen separations. ${ }^{32}$ Pure-gas ethylene/ethane separation properties of PIM-materials have only been reported for a very limited number of polymers. ${ }^{33-35}$ PIM-1 (Fig. 1a) was reported to have high ethylene permeability of 1640 Barrer but with very low $\mathrm{C}_{2} \mathrm{H}_{4} / \mathrm{C}_{2} \mathrm{H}_{6}$ selectivity of $1.8 .^{34} \mathrm{~A}$ polyimide-based PIM, (a)<smiles>CCc1c2c(C)c(C)c(C#N)c1Oc1cc3c(cc1O2)Oc1cc2c(cc1C3(C)C)C1(CC(C)C(C)(C)C1)C2(C)C</smiles>

(b)<smiles>CN1C(=O)c2ccc(C(F)(F)C(F)(F)F)cc2C1=O</smiles>

(c)<smiles>Cc1nc2cc3c(cc2o1)C1(CC3(C)C)CC(C)(C)c2cc3nc(-c4ccc(C(F)(F)C(F)(F)F)cc4)oc3cc21</smiles>

(d)

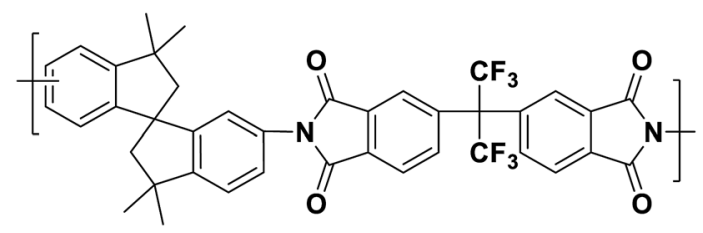

Fig. 1 Chemical structure of: (a) PIM-1; (b) PIM-6FDA-OH; (c) PIMPBO (d) PIM-6FDA.

PIM-6FDA-OH (Fig. 1b), exhibited much lower ethylene permeability of 5.5 Barrer with an ethylene/ethane selectivity of $4 .{ }^{35}$

Interestingly, only a few reports are available on the formation and gas separation properties of CMS membranes made from intrinsically microporous polymer precursors. ${ }^{34-38}$ The CMS membrane formed at $800{ }^{\circ} \mathrm{C}$ from the prototype ladder polymer of intrinsic microporosity, PIM-1, demonstrated significant densification upon formation of its CMS structure with a dominant crosslinking/sintering effect, resulting in a 1000 -fold reduction in the ethylene permeability compared to the pristine PIM-1 from 1640 to 1.3 Barrer. The PIM-1-derived CMS membrane had a pure-gas $\mathrm{C}_{2} \mathrm{H}_{4} / \mathrm{C}_{2} \mathrm{H}_{4}$ selectivity of 13 , similar to that reported for a CMS made from low-freevolume Matrimid ${ }^{\circledR}$ polyimide at $675{ }^{\circ} \mathrm{C}^{16}$ In another study, a CMS membrane derived from a hydroxyl-functionalized PIM polyimide at $800{ }^{\circ} \mathrm{C}$, PIM-6FDA-OH, showed an ideal pure-gas $\mathrm{C}_{2} \mathrm{H}_{4} / \mathrm{C}_{2} \mathrm{H}_{6}$ selectivity of $\sim 18$ measured at 2 bar. $^{35}$ When tested under mixed-gas conditions with an equimolar feed at a pressure of 20 bar and $35{ }^{\circ} \mathrm{C}$, the $\mathrm{C}_{2} \mathrm{H}_{4} / \mathrm{C}_{2} \mathrm{H}_{6}$ selectivity dropped to 
8.3 with a $\mathrm{C}_{2} \mathrm{H}_{4}$ permeability of 9.6 Barrer. $^{35}$ The CMS precursor polyimide, PIM-6FDA-OH, contained hydroxyl groups in ortho position to the imide linkages. Consequently, its pyrolysis process proceeded in three major stages: (i) transformation of the $o-\mathrm{OH}$-functionalized polyimide to the corresponding polybenzoxazole (PBO) by thermal rearrangement at $\sim 400{ }^{\circ} \mathrm{C}$ (Fig. 1c) - in this step, an opening of the micropore structure is typically observed with a significant increase in gas permeability and decrease in selectivity; ${ }^{23,39-41}$ (ii) partial carbonization of the $\mathrm{PBO}$ from $\sim 500-550{ }^{\circ} \mathrm{C}$, characterized by creation of larger pores and increase in permeability; (iii) development of an amorphous, ultramicroporous carbon structure from $600-800{ }^{\circ} \mathrm{C}$ with decrease in pore size and permeability but significant increase in selectivity. ${ }^{36}$ The last two steps are equivalent to the CMS formation of polyimides that do not undergo PBO formation during the pyrolysis process. ${ }^{16,42}$

In this study, a new hydroxyl-free spirobisindane-based polyimide precursor, PIM-6FDA (Fig. 1d), was used to finetune the morphology of high-performance CMS membranes for $\mathrm{C}_{2} \mathrm{H}_{4} / \mathrm{C}_{2} \mathrm{H}_{6}$ separation. Pure- and mixed-gas permeation tests were conducted with an equimolar feed up to 20 bar and $35{ }^{\circ} \mathrm{C}$ for the $800{ }^{\circ} \mathrm{C}$ CMS membrane derived from PIM6FDA to determine its potential for industrial ethylene/ethane separation.

\section{Experimental}

\section{Materials and characterization methods}

Pristine PIM-6FDA (Fig. 1d) was synthesized following the same general procedure previously reported for PIM-6FDA-OH. ${ }^{43} 4,4^{\prime}$ (Hexafluoroisopropylidene)diphthalic anhydride (6FDA, 99\%) was purchased from Sigma-Aldrich and used after vacuum sublimation. 3,3,3', $3^{\prime}$-Tetramethyl-1,1'-spirobisindane-6, $6^{\prime}\left(5^{\prime}\right)$ diamine was synthesized according to a previously reported method. ${ }^{44}$ PIM-6FDA was obtained as light yellow filaments with a yield of $95 \%$. ${ }^{1} \mathrm{H}$ NMR $\left(500 \mathrm{MHz}, \mathrm{CDCl}_{3}\right): \delta 8.06(\mathrm{~d}, 2 \mathrm{H}, J=8.05$ $\mathrm{Hz}), 7.93$ (s, 2H), 7.89 (d, 2H, $J=7.65 \mathrm{~Hz}), 7.19-7.20(\mathrm{~m}, 4 \mathrm{H})$, $7.02(\mathrm{~d}, 2 \mathrm{H}, J=8.65 \mathrm{~Hz}), 2.44(\mathrm{~d}, 2 \mathrm{H}, J=13.2 \mathrm{~Hz}), 2.36(\mathrm{~d}, 2 \mathrm{H}$, $J=13.2 \mathrm{~Hz}$ ), 1.43 (s, 6H), 1.39 (s, 6H); FT-IR (powder, $\nu, \mathrm{cm}^{-1}$ ): 2959, 2928, 2854 (m, C-H vibration), 1786, 1717, 1620 (vs., imide), 1481, 1358, 1261, 1186 (s, aromatic $\left.\mathrm{C}^{\circ} \mathrm{C}\right), 720$ (s, C-F); $M_{\mathrm{n}}$ $=2.1 \times 10^{4} \mathrm{~g} \mathrm{~mol}^{-1} ; M_{\mathrm{w}}=6.1 \times 10^{4} \mathrm{~g} \mathrm{~mol}^{-1} ; \mathrm{PDI}=2.9 . T_{\mathrm{d}}=$ $480{ }^{\circ} \mathrm{C} ; S_{\mathrm{BET}}=260 \mathrm{~m}^{2} \mathrm{~g}^{-1}$.

${ }^{1} \mathrm{H}$ NMR spectra (500 MHz) were recorded on a Bruker DRX spectrometer using tetramethylsilane as the internal standard. Chemical shifts $(\delta)$ are reported in ppm. The molecular weight of PIM-6FDA was determined by gel permeation chromatography (Malvern HT-350) using chloroform as an eluent. A thermogravimetric analyzer (TGA, TA Instruments) was used to measure polymer weight loss as a function of heat treatment temperature. Evolved gases were qualitatively analyzed with a quadrupole mass spectrometer (Hiden Analytical) coupled to the TGA with $\mathrm{N}_{2}$ as the carrier gas. Fourier transform infrared (FTIR) spectra were acquired using a Thermo Nicolet iS10 infrared spectrometer. X-ray diffraction (XRD) scattering was conducted on a Bruker D8
Advance diffractometer. Raman spectra of the carbonized films were obtained with a Horiba LabRam HR visible microscope at $473 \mathrm{~nm}$ excitation wavelength. The BET surface area was determined by $\mathrm{N}_{2}$ sorption at $-196{ }^{\circ} \mathrm{C}$ using a Micromeritics ASAP-2020. Powder polymer samples were degassed under high vacuum at $150{ }^{\circ} \mathrm{C}$ for 24 hours prior to analysis. Ethylene and ethane sorption isotherms were determined with a Hiden IGA apparatus in the pressure range from 1 to 15 bar at $35{ }^{\circ} \mathrm{C}$.

\section{Membrane fabrication}

Dense PIM-6FDA polyimide films were made by slowly evaporating $3 \% \mathrm{w} / \mathrm{v}$ polymer/THF solution from a leveled and covered Petri dish for three days. The films were then air dried for $12 \mathrm{~h}$ and further heat conditioned at $250{ }^{\circ} \mathrm{C}$ for $24 \mathrm{~h}$ under vacuum to remove traces of solvent. Thermal gravimetric analysis confirmed that the films were solvent-free. The final film thickness was $90 \mu \mathrm{m}( \pm 1 \mu \mathrm{m})$ as measured with a digital micrometer. The effective areas of the films prior to permeation measurements were determined with a scanner and image processing software.

CMS membranes were made by placing $25 \mathrm{~mm}$ diameter PIM-6FDA films inside a Carbolite three-zone tube furnace in a quartz tube supplied with $1000 \mathrm{~cm}^{3}$ (STP) $\mathrm{min}^{-1}$ of $\mathrm{N}_{2}$ from a mass flow controller. The temperature was measured with a thermocouple placed directly adjacent to the film sample. The concentration of oxygen exiting the furnace was less than $2 \mathrm{ppm}$ as continuously measured with an oxygen analyzer (Cambridge Sensotec Rapidox 3100). The furnace temperature was ramped at $3{ }^{\circ} \mathrm{C} \mathrm{min}^{-1}$ and then held isothermally for 30 minutes at each desired pyrolysis temperature. After this isothermal stage, the furnace was allowed to cool down to room temperature. The resulting CMS films were immediately stored in a desiccator under vacuum to prevent any significant oxygen chemisorption or water vapor sorption prior to gas permeation testing. These measures were used to ensure data reproducibility.

\section{Permeation measurements}

Pure- and mixed-gas permeation experiments were performed at $35{ }^{\circ} \mathrm{C}$ with feed pressures up to 20 bar in a constant-volume/ variable-pressure apparatus as described in detail elsewhere. ${ }^{\mathbf{4 5}}$ The films were masked with special care to prevent damage under vacuum as previously described. ${ }^{46}$ Samples were degassed under high vacuum for at least $24 \mathrm{~h}$ to remove adsorbed gases. Pure-gas permeability was calculated according to the following equation:

$$
P_{i}=\frac{V_{\mathrm{d}} l}{P_{\mathrm{U}} T R A} \frac{\mathrm{d} p_{i}}{\mathrm{~d} t}
$$

where $P_{i}$ is the pure-gas permeability in Barrer $(1$ Barrer $=1 \times$ $10^{-10} \mathrm{~cm}^{3}$ (STP) $\mathrm{cm} \mathrm{cm}^{-2} \mathrm{~s}^{-1} \mathrm{cmHg}^{-1}$ ), $V_{\mathrm{d}}$ is the downstream volume, $l$ is the membrane thickness, $P_{\mathrm{U}}$ is the upstream pressure, $T$ is the temperature in absolute units, $R$ is the gas constant, $A$ is the active permeation area and $\mathrm{d} p_{\mathrm{i}} / \mathrm{d} t$ is the steady-state rise in pressure with respect to time. Pure-gas 
selectivity was calculated as the ratio of the pure-gas permeabilities:

$$
\alpha_{i / j}=\frac{P_{i}}{P_{j}}
$$

The mixed-gas permeability was measured with a $50: 50 \mathrm{v} / \mathrm{v}$ ethylene/ethane mixture by the general technique described by O'Brien et al. ${ }^{47}$ The stage-cut, that is, the permeate to feed flow rate, was less than $1 \%$. Hence, the feed and residue concentrations were essentially equivalent and potential concentration polarization effects were minimized. The feed and permeate compositions were determined with an Agilent 3000A Micro GC. Mixed-gas permeabilities were calculated as follows:

$$
P_{i}=\frac{y_{i} V_{\mathrm{d}} l}{x_{i} P_{\mathrm{U}} T R A} \frac{\mathrm{d} p}{\mathrm{~d} t}
$$

where $P_{i}$ is the permeability of component $i, y_{i}$ and $x_{i}$ are the molar fractions of $i$ in the permeate and feed, respectively. Finally, the mixed-gas selectivity was calculated by:

$$
\alpha_{i / j}=\frac{y_{i} / x_{i}}{y_{j} / x_{j}}
$$

\section{Gravimetric pure-gas sorption}

Gravimetric sorption isotherms for pure $\mathrm{C}_{2} \mathrm{H}_{4}$ and $\mathrm{C}_{2} \mathrm{H}_{6}$ in the pressure range 1 to 15 bar were determined at $35{ }^{\circ} \mathrm{C}$. To determine the sorption capacity of the 6FDA-PIM and the CMS samples on a volumetric basis, their density was determined gravimetrically by measuring the weight, area, and film thickness (Table S1†).

Gas sorption in glassy polymers can be described by the dualmode sorption model: ${ }^{48}$

$$
C=K_{\mathrm{D}} p+\frac{C_{\mathrm{H}}^{\prime} b p}{1+b p}
$$

where $C$ is the total gas concentration in the glassy polymer, $K_{\mathrm{d}}$ is the Henry's law coefficient, $C^{\prime}{ }_{\mathrm{H}}$ is the Langmuir hole capacity, $b$ is the interaction parameter, and $p$ is the gas pressure. Gas isotherms of microporous carbon materials are typically expressed by the Langmuir model: ${ }^{49}$

$$
C=\frac{C^{\prime}{ }_{\mathrm{H}} b p}{1+b p}
$$

The gas solubility can be calculated for a fixed thermodynamic state as:

$$
S=\frac{C}{p}
$$

Then, the diffusion coefficient or diffusivity, $D$, can be estimated from the basic permeability definition as:

$$
D=\frac{P}{S}
$$

\section{Results and discussion}

\section{Physical properties of PIM-6FDA}

The molecular weight $\left(M_{\mathrm{n}}\right)$ of PIM-6FDA was $\sim 6.1 \times 10^{4} \mathrm{~g} \mathrm{~mol}^{-1}$ with a polydispersity index (PDI) of 2.9. The PIM-6FDA film annealed at $250{ }^{\circ} \mathrm{C}$ had a density of $1.24 \mathrm{~g} \mathrm{~cm}^{-3}$, which was slightly lower than that of its analogue PIM-6FDA-OH $(\rho=1.28 \mathrm{~g}$ $\mathrm{cm}^{-3}$ ) annealed under the same conditions (Table S1 $\dagger$ ). The degradation profiles of PIM-6FDA and PIM-6FDA-OH as a function of temperature are distinctively different, as shown in Fig. 2. PIM-6FDA remained in its polymeric glassy state prior to the onset of carbonization above $500{ }^{\circ} \mathrm{C}$ according to the gain in Raman sensitivity of the membranes (Fig. S1 $\dagger$ ). The onset of degradation in PIM-6FDA commenced at $\sim 480{ }^{\circ} \mathrm{C}$ and its backbone decomposed in a single stage that reached a maximum rate at $\sim 550{ }^{\circ} \mathrm{C}$ with $\mathrm{H}_{2} \mathrm{O}$ and $\mathrm{CO}_{2}$ as the main decomposition products. The PIM-6FDA membranes heated at $500{ }^{\circ} \mathrm{C}$ suffered a significant $23 \%$ weight loss after a $30 \mathrm{~min}$ isothermal soak (Fig. S2 $\dagger$ ). This degradation stage can be attributed to the cleavage of the polyimide rings and the creation of polar segments in the vestigial chains via free radicals

(a)

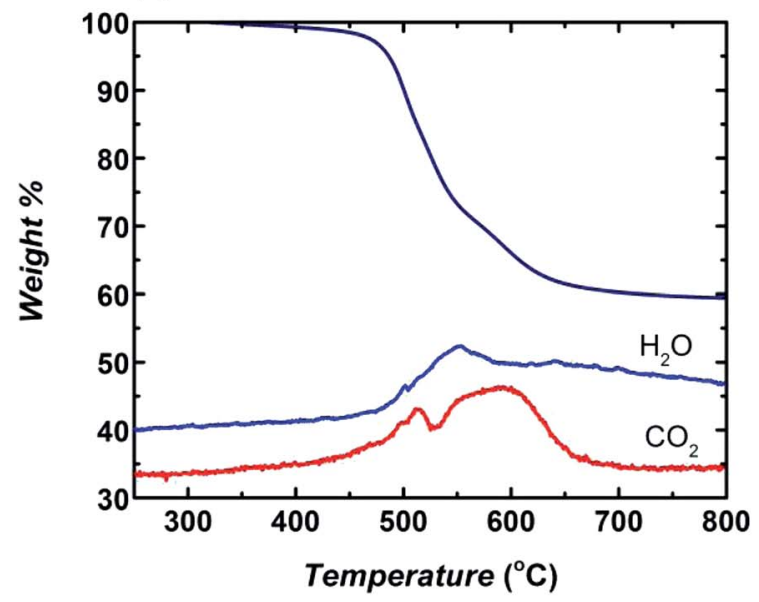

(b)

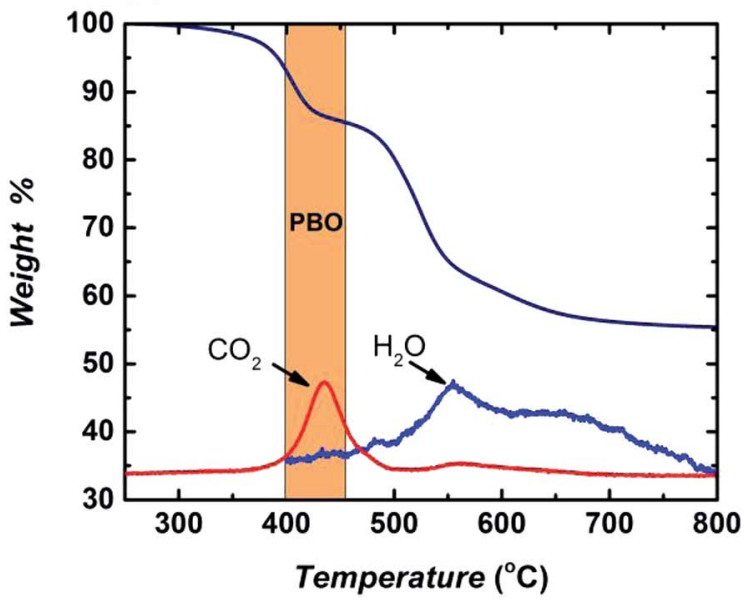

Fig. 2 Weight loss and mass spectra of evolved gases during the degradation of (a) PIM-6FDA and (b) PIM-6FDA-OH. Ramping rate was $3{ }^{\circ} \mathrm{C} \mathrm{min}^{-1}$ under $\mathrm{N}_{2}$ atmosphere. 
mechanism. The decrease in the infrared spectra intensity confirmed the elimination of most methyl, carbonyl, and hexafluoroisopropylidene moieties as the samples were treated at higher temperatures (Fig. S3†). PIM-6FDA-OH showed a lower degradation temperature starting around $350{ }^{\circ} \mathrm{C}$, and more importantly, its degradation profile proceeded in two stages. In the first stage, between $400-450{ }^{\circ} \mathrm{C}$ the polyimide was thermally converted to a polybenzoxazole, as previously reported for a wide variety of polyimides bearing an ortho-hydroxyl group adjacent to the imide linkage..$^{23,39-41}$ This stage is characterized by the evolution of $\mathrm{CO}_{2}$ as a reaction by-product, as clearly shown in Fig. 2b. In the second stage, at temperatures higher than $500{ }^{\circ} \mathrm{C}$, amorphous carbon was formed by main chain degradation as evidenced by the evolution of water. In the first stage of PIM-6FDA pyrolysis at $500{ }^{\circ} \mathrm{C}$, the partially degraded polymer shows a widening in average $d$-spacing ranging from 4.11-6.26 $\AA$, as indicated by the broadening of the amorphous peak of the pristine polyimide originally centered at $5.51 \AA$. This result is consistent with a significant increase in $\mathrm{C}_{2} \mathrm{H}_{4}$ permeability and drop in $\mathrm{C}_{2} \mathrm{H}_{4} / \mathrm{C}_{2} \mathrm{H}_{6}$ selectivity, as discussed below.

The carbonization process most likely induced a more ordered graphitic structure and ultramicroporosity into the CMS membranes at higher pyrolysis temperature as indicated by the narrowing in average $d$-spacing of the main amorphous peak in the XRD spectra in Fig. 3. The broad amorphous peak with the average $d$-spacing ranging from 4.11-6.26 $\AA$ at lower scattering angle $\left(2\right.$-theta $\left.=10-30^{\circ}\right)$ showing in CMS $500{ }^{\circ} \mathrm{C}$ shrank to a more defined peak with a much narrower range of average $d$-spacing of the bimodal distribution (i.e. 3.75-4.34 $\AA$ ) for CMS $600{ }^{\circ} \mathrm{C}$. In addition, a new peak appeared at a $d$-spacing of $2.05 \AA$ corresponding to the $\left(\begin{array}{lll}1 & 0 & 0\end{array}\right)$ plane of graphite layers. Such dramatic changes in XRD spectra indicate formation of a more ordered carbonaceous structure at higher pyrolysis temperature. Samples treated at $800{ }^{\circ} \mathrm{C}$ did not suffer significant additional weight loss, indicating that the membranes were mainly comprised of a honeycomb-arranged carbon skeleton with no thermally liable groups. Most importantly, the PIM-6FDA-based CMS generated at $800{ }^{\circ} \mathrm{C}$ had only one main

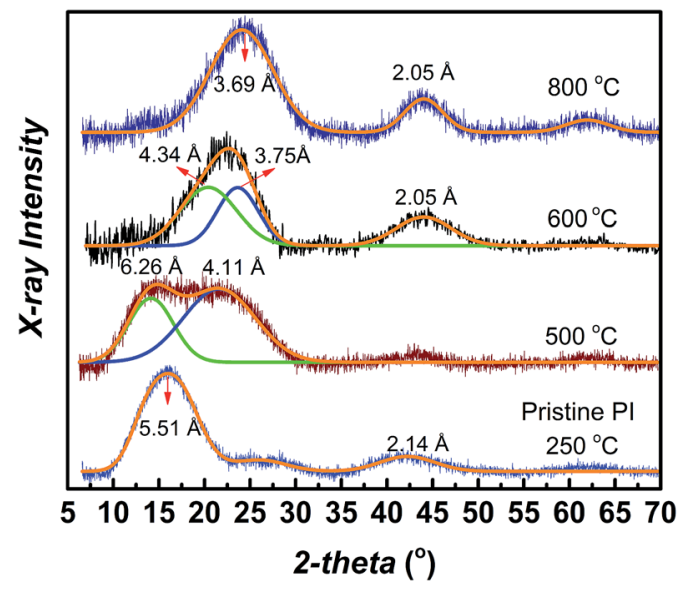

Fig. 3 XRD spectra of PIM-6FDA (pristine PI) and CMS membranes for each isothermal stage of carbonization. amorphous peak with even smaller $d$-spacing centered at $3.69 \AA$, and the peak at $d$-spacing $2.05 \AA$ became more pronounced, indicating generation of a more ordered graphitic structure in the resulting CMS membrane. This qualitative methodology using XRD tracked a definite improvement in tightening the membrane structure and increasing the ultramicroporous characteristics of the PIM-6FDA films after carbonization, and consequently, their molecular sieving capabilities. The subtle difference in the membrane structure of the 600 and $800{ }^{\circ} \mathrm{C}$ treated CMS membranes had significant effects on their gas separation performance. The $800{ }^{\circ} \mathrm{C}$-treated CMS membrane consisted of a more tightly sintered structure with greatly enhanced $\mathrm{C}_{2} \mathrm{H}_{4} / \mathrm{C}_{2} \mathrm{H}_{6}$ selectivity but at the cost of lower ethylene permeability, as discussed below.

\section{Pure-gas ethylene/ethane permeation, sorption and diffusion}

The pure-gas $\mathrm{C}_{2} \mathrm{H}_{4}$ and $\mathrm{C}_{2} \mathrm{H}_{6}$ permeabilities of the thermally annealed PIM-6FDA film and its pyrolyzed CMS derivatives were determined at 2 bar and $35^{\circ} \mathrm{C}$ (Table 1). The pristine PIM-6FDA film heat-treated at $250{ }^{\circ} \mathrm{C}$ showed an ethylene permeability of 7.9 Barrer with an ethylene/ethane permselectivity of 3.6. After partial degradation of the polymer backbone at $500{ }^{\circ} \mathrm{C}$, the ethylene permeability of the resulting CMS membrane increased by a factor of $\sim 40$ to 328 Barrer mainly due to the generation of new pores and pore opening (indicated by widening of average $d$-spacing in the range of $\sim 4.1-6.3 \AA$ as shown in XRD spectra (Fig. 3)); however, the selectivity decreased from 3.6 to 2.1. Heat treatment at higher temperatures reduced permeability as a result of the chain compaction confirmed by XRD. For membranes treated at 600 to $800{ }^{\circ} \mathrm{C}$, the ethylene permeability decreased sharply from 77 to 3.0 Barrer, whereas ethylene/ ethane selectivity increased significantly from 4.1 to 25 .

To gain further insights to the contributions of gas solubility and diffusivity on the permeability and permselectivity of PIM6FDA-based CMS membranes, gravimetric ethylene and ethane sorption measurements were carried out at $35{ }^{\circ} \mathrm{C}$ up to 15 bar. The films were dried in a vacuum oven at $120^{\circ} \mathrm{C}$ for at least $12 \mathrm{~h}$ to remove any moisture. The sample cell was then evacuated for 1 day prior to testing and evacuated for $24 \mathrm{~h}$ after completion of each gas isotherm. The pure-gas sorption isotherms for $\mathrm{C}_{2} \mathrm{H}_{4}$ and $\mathrm{C}_{2} \mathrm{H}_{6}$ are shown in Fig. S4. $\dagger$ The CMS sorption isotherms followed Langmuir behavior with significantly higher $\mathrm{C}_{2} \mathrm{H}_{4}$ and

Table 1 Pure-gas ethylene and ethane permeability and $\mathrm{C}_{2} \mathrm{H}_{4} / \mathrm{C}_{2} \mathrm{H}_{6}$ permselectivity of PIM-6FDA and CMS membranes treated at various temperatures $\left(p=2 \mathrm{~atm} ; T=35^{\circ} \mathrm{C}\right)$

\begin{tabular}{llll}
\hline & \multicolumn{2}{l}{$\begin{array}{l}\text { Permeability }^{a} \\
\text { (Barrer) }\end{array}$} & \\
\cline { 2 - 3 } & $\mathrm{C}_{2} \mathrm{H}_{4}$ & $\mathrm{C}_{2} \mathrm{H}_{6}$ & \\
Membrane type & 7.9 & $\alpha_{\mathrm{P}}$ & $\mathrm{C}_{2} \mathrm{H}_{4} / \mathrm{C}_{2} \mathrm{H}_{6}$ \\
\hline PIM-6FDA $250{ }^{\circ} \mathrm{C}$ & 328 & 2.19 & 3.6 \\
$\mathrm{CMS} 500{ }^{\circ} \mathrm{C}$ & 77 & 156 & 2.1 \\
$\mathrm{CMS} 600{ }^{\circ} \mathrm{C}$ & 3.0 & 18.8 & 4.1 \\
$\mathrm{CMS} 800^{\circ} \mathrm{C}$ & 0.12 & 25
\end{tabular}

${ }^{a} 1$ Barrer $=10^{-10} \mathrm{~cm}^{3}(\mathrm{STP}) \mathrm{cm} \mathrm{cm}^{-2} \mathrm{~s}^{-1} \mathrm{cmHg}^{-1}$. 
$\mathrm{C}_{2} \mathrm{H}_{6}$ sorption capacity than their PIM-6FDA polyimide precursor. The dual-mode and Langmuir fitting parameters are listed in Table S2. $\uparrow$ The ethylene solubility at 2 bar was $0.19,0.34$, 0.52 , and $0.66 \mathrm{~cm}^{3} \mathrm{~cm}^{-3} \mathrm{cmHg}^{-1}$ for the pristine PIM-6FDA, 500, 600 , and $800{ }^{\circ} \mathrm{C}$-treated CMS membranes, respectively. As expected, the sorption uptake for ethane was very similar to that of ethylene at a given pressure; hence, the $\mathrm{C}_{2} \mathrm{H}_{6} / \mathrm{C}_{2} \mathrm{H}_{6}$ solubility selectivity was essentially 1 , as shown in Table 2 . Consequently, the $\mathrm{C}_{2} \mathrm{H}_{6} / \mathrm{C}_{2} \mathrm{H}_{6}$ permselectivity of the CMS membranes was completely controlled by their diffusivity selectivity (Table 3 ).

The diffusivities of ethylene and ethane were calculated from the measured permeability and gravimetrically determined solubility at 2 bar and $35{ }^{\circ} \mathrm{C}$ from the relationship $D=P / S$. Because of the formation of larger micropores in the transition range from the pristine polymer to the CMS membrane pyrolized at $500{ }^{\circ} \mathrm{C}$, the diffusivity increased 23-fold from 42 to $970 \times 10^{-10} \mathrm{~cm}^{2} \mathrm{~s}^{-1}$; simultaneously, the diffusivity selectivity decreased from 3.7 to 2 . Further heat treatment to $600{ }^{\circ} \mathrm{C}$ and $800{ }^{\circ} \mathrm{C}$ resulted in smaller average pore size, drop in diffusivity and increase in selectivity. Specifically, CMS membranes made at $800{ }^{\circ} \mathrm{C}$ exhibited outstanding molecular sieving properties with a pure-gas $\mathrm{C}_{2} \mathrm{H}_{6} / \mathrm{C}_{2} \mathrm{H}_{6}$ diffusivity selectivity of 23.5 . The 6-fold increase in diffusivity selectivity from 3.9 for $600{ }^{\circ} \mathrm{C}$ to 23.5 for $800^{\circ} \mathrm{C}$-treated CMS membranes can be explained by the shift in their average $d$-spacing values from the range of 3.75$4.34 \AA\left(600{ }^{\circ} \mathrm{C}\right)$ to $3.69 \AA\left(800{ }^{\circ} \mathrm{C}\right)$, as shown in Fig. 3. Apparently, the small reduction in the average $d$-spacing of CMS membranes resulted in a very strong molecular sieving effect between ethylene and ethane in the $800{ }^{\circ} \mathrm{C}$-treated CMS membrane. The size of ethylene and ethane are estimated to be $3.75 \AA$ and 3.85 $\AA$, respectively, using space-filling CPK models and calibrated "slits". ${ }^{50}$ The highest $\mathrm{C}_{2} \mathrm{H}_{6} / \mathrm{C}_{2} \mathrm{H}_{6}$ selectivity exhibited in CMS membrane at $800{ }^{\circ} \mathrm{C}$ is not a coincidence because its unique CMS structure with average $d$-spacing of $3.69 \AA$ has a close match with the ideal sieving effects for ethylene and ethane. Because its ethylene permeability of 3 Barrer was relatively low, higher temperature pyrolysis conditions to potentially further enhance the selectivity were not pursued in this study.

\section{Mixed-gas permeation}

Because the PIM-6FDA sample carbonized at $800{ }^{\circ} \mathrm{C}$ showed the highest pure-gas selectivity, additional experiments were performed with a $50: 50 \mathrm{v} / \mathrm{v}$ ethylene/ethane mixture at $35^{\circ} \mathrm{C}$ as a function of feed pressure. The results are summarized in

Table 2 Ethylene and ethane solubility and $\mathrm{C}_{2} \mathrm{H}_{4} / \mathrm{C}_{2} \mathrm{H}_{6}$ solubility selectivity of PIM-6FDA and CMS membranes treated at various temperatures $\left(p=2 \mathrm{~atm} ; T=35^{\circ} \mathrm{C}\right)$

\begin{tabular}{llll}
\hline & \multicolumn{2}{l}{$\begin{array}{l}\text { Solubility } \\
\left(\mathrm{cm}^{3} \mathrm{~cm}^{-3} \mathrm{cmHg}^{-1}\right)\end{array}$} & \\
\cline { 2 - 3 } & $\mathrm{C}_{2} \mathrm{H}_{4}$ & $\mathrm{C}_{2} \mathrm{H}_{6}$ & $\mathrm{C}_{2} \mathrm{H}_{4} / \mathrm{C}_{2} \mathrm{H}_{6}$ \\
Membrane type & 0.19 & 0.19 & 1.0 \\
\hline PIM-6FDA 250 ${ }^{\circ} \mathrm{C}$ & 0.34 & 0.32 & 1.05 \\
CMS 500 ${ }^{\circ} \mathrm{C}$ & 0.52 & 0.50 & 1.04 \\
$\mathrm{CMS} 600{ }^{\circ} \mathrm{C}$ & 0.66 & 0.62 & 1.06 \\
CMS $800{ }^{\circ} \mathrm{C}$ & & &
\end{tabular}

Table 3 Ethylene and ethane diffusivity and $\mathrm{C}_{2} \mathrm{H}_{4} / \mathrm{C}_{2} \mathrm{H}_{6}$ diffusivity selectivity of PIM-6FDA and CMS membranes treated at various temperatures ( $\left.p=2 \mathrm{~atm} ; T=35^{\circ} \mathrm{C}\right)$

\begin{tabular}{llll}
\hline & \multicolumn{2}{l}{$\begin{array}{l}\text { Diffusivity } \\
\left(10^{-10} \mathrm{~cm}^{2} \mathrm{~s}^{-1}\right)\end{array}$} & \\
\cline { 2 - 3 } & $\mathrm{C}_{2} \mathrm{H}_{4}$ & $\mathrm{C}_{2} \mathrm{H}_{6}$ & \multicolumn{1}{c}{$\alpha_{\mathrm{D}}$} \\
Membrane type & 42 & 11.5 & $\mathrm{C}_{2} \mathrm{H}_{4} / \mathrm{C}_{2} \mathrm{H}_{6}$ \\
\hline PIM-6FDA $250{ }^{\circ} \mathrm{C}$ & 970 & 490.5 & 3.7 \\
CMS $500{ }^{\circ} \mathrm{C}$ & 150 & 38.0 & 2.0 \\
CMS $600{ }^{\circ} \mathrm{C}$ & 4.6 & 0.195 & 23.9 \\
CMS $800^{\circ} \mathrm{C}$ & & & \\
\hline
\end{tabular}

Table 4. The overall response to increasing the upstream pressure indicated a relatively small permeability enhancement for both hydrocarbons. Ethylene permeability increased from 3.0 to 3.2 Barrer, whereas ethane permeability increased from 0.167 to 0.205 Barrer over the feed pressure range of 4 to 20 bar. The mixed-gas $\mathrm{C}_{2} \mathrm{H}_{4} / \mathrm{C}_{2} \mathrm{H}_{6}$ selectivity of the CMS membrane dropped only slightly from 18 to $\mathbf{1 5 . 6}$ by increasing the feed pressure from 4 to 20 bar.

The time dependence of the mixed-gas permeation experiments is shown in Fig. S5. $\dagger$ In order to reach pseudo steady-state permeation conditions for each feed pressure over the range of 4 to 20 bar it took a total time of about 80 days. This significant time-dependent effect of the physical state of the CMS membrane tested at each pressure point on the mixed-gas permeation properties can possibly be attributed to a small matrix dilation of its ultramicropores. This subtle dilation resulted in the observed small increase in mixed-gas permeability of the two hydrocarbons and a concurrent small selectivity drop. This behavior agreed with previous mixed-gas permeation results for ethylene/ethane and $\mathrm{CO}_{2} / \mathrm{CH}_{4}$ obtained for the $800{ }^{\circ} \mathrm{C}$ heat-treated CMS membrane derived from PIM-6FDA-OH. ${ }^{35,37}$ However, the drop in selectivity is less pronounced compared to the CMS membrane derived from its $\mathrm{OH}$-functionalized counterpart, as shown in the $\mathrm{C}_{2} \mathrm{H}_{4} / \mathrm{C}_{2} \mathrm{H}_{6}$ upper bound Robeson plot (Fig. 4), possibly due to its more tightly packed CMS structure as discussed in the following section.

\section{The effect of PIM-6FDA polyimide precursor on CMS performance}

Similar to PIM-6FDA-OH ${ }^{35}$ increasing the pyrolysis temperature resulted in less permeable but highly $\mathrm{C}_{2} \mathrm{H}_{4} / \mathrm{C}_{2} \mathrm{H}_{6}$ selective CMS

Table 4 Mixed-gas ethylene and ethane permeability and $\mathrm{C}_{2} \mathrm{H}_{4} / \mathrm{C}_{2} \mathrm{H}_{6}$ permselectivity of a PIM-6FDA-derived CMS membrane treated at $800{ }^{\circ} \mathrm{C}$ as a function of feed pressure (feed composition: 50 vol\% $\mathrm{C}_{2} \mathrm{H}_{4}: 50$ vol\% $\mathrm{C}_{2} \mathrm{H}_{6} ; T=35^{\circ} \mathrm{C}$ )

\begin{tabular}{llll}
\hline \multirow{2}{*}{$\begin{array}{l}\text { Feed pressure } \\
\text { (Bar) }\end{array}$} & \multicolumn{2}{l}{ Permeability (Barrer) } & \\
\cline { 2 - 3 } & $\mathrm{C}_{2} \mathrm{H}_{4}$ & $\mathrm{C}_{2} \mathrm{H}_{6}$ & $\alpha_{\mathrm{P}}$ \\
\hline 4 & 3.02 & 0.168 & $\mathrm{C}_{2} \mathrm{H}_{4} / \mathrm{C}_{2} \mathrm{H}_{6}$ \\
8 & 3.11 & 0.181 & 17.9 \\
12 & 3.13 & 0.187 & 17.2 \\
20 & 3.21 & 0.205 & 16.7 \\
& & & 15.6
\end{tabular}




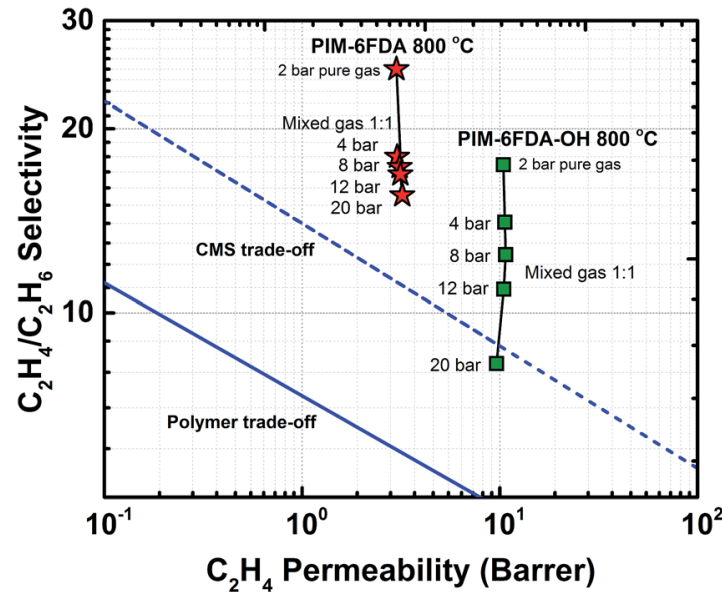

Fig. $4 \mathrm{C}_{2} \mathrm{H}_{4} / \mathrm{C}_{2} \mathrm{H}_{6}$ mix-gas permeation results for PIM-6FDA and PIM6FDA-OH CMS membranes made at $800^{\circ} \mathrm{C}$ and location on pure-gas polymer and CMS upper bound plots. ${ }^{35}$

membranes made from PIM-6FDA, as shown in Fig. 4. However, the $800{ }^{\circ} \mathrm{C}$ CMS derived from OH-free PIM-6FDA polyimide has higher $\mathrm{C}_{2} \mathrm{H}_{4} / \mathrm{C}_{2} \mathrm{H}_{6}$ selectivity compared to its $\mathrm{OH}$-functionalized counterpart PIM-6FDA-OH. The XRD spectra show a broader amorphous peak with average $d$-spacing at $3.75 \AA$ for PIM-6FDA$\mathrm{OH}$ as compared to its non-functionalized counterpart PIM-6FDA (3.69 $\AA$ ), indicating formation of a more ordered CMS membrane structure with the OH-free PIM-6FDA precursor (see Fig. S6 $\dagger$ ). Raman spectra of both CMS membranes show the presence of both $\mathrm{D}$ and $\mathrm{G}$ bands (see Fig. S7†), suggesting that CMS membranes consist of highly disordered graphene-like sheets. However, a slightly lower D to G ratio (2.08) was found in PIM6FDA compared to PIM-6FDA-OH (2.14) (see Fig. S7 and Table $\mathrm{S} 3 \dagger)$, which suggests an increase in order and graphitization for $\mathrm{CMS}$ at $800{ }^{\circ} \mathrm{C}$ derived from PIM-6FDA as compared to PIM6FDA-OH. This confirms the observed difference in XRD spectra between the two CMS membranes although using Raman spectra should be taken with caution (see Table S3 in ESI $\dagger$ ). Therefore, the enhanced $\mathrm{C}_{2} \mathrm{H}_{4} / \mathrm{C}_{2} \mathrm{H}_{6}$ selectivity can be attributed to a more ordered graphitic structure obtained for OH-free PIM6FDA CMS membranes. The presence of functional $\mathrm{OH}$ groups in the polymer precursor has shown detrimental effects for $800{ }^{\circ} \mathrm{C}$ CMS membrane performance for $\mathrm{C}_{2} \mathrm{H}_{4} / \mathrm{C}_{2} \mathrm{H}_{6}$ separation; however, the reason is not completely clear at this stage. It is likely that the additional larger pores created during PBO transformation for PIM-6FDA-OH precursor CMS membranes during the pyrolysis process undermine or slow down the formation of a more tightly sintered CMS structure with more optimum $\mathrm{C}_{2} \mathrm{H}_{4}$ / $\mathrm{C}_{2} \mathrm{H}_{6}$ molecular sieving capabilities. It is possible that higher pyrolysis temperature is needed for PIM-6FDA-OH precursor to create a more ordered CMS structure with higher $\mathrm{C}_{2} \mathrm{H}_{4} / \mathrm{C}_{2} \mathrm{H}_{6}$ selectivity. However, the weak mechanical strength of the resulting CMS membranes prohibited any further exploration.

\section{Conclusions}

In this work, a novel polyimide of intrinsic microporosity, PIM6FDA, was employed to generate isotropic CMS membranes with excellent performance for ethylene/ethane separation. Development of a fine-tuned ultramicroporous structure from the PIM-6FDA precursor at $800{ }^{\circ} \mathrm{C}$ produced a superior ethylene/ ethane diffusion-selective membrane. The CMS membrane derived from PIM-6FDA at $800{ }^{\circ} \mathrm{C}$ exhibited a pure-gas selectivity of 25 with an ethylene permeability of 3 Barrer (measured at 2 bar and $35^{\circ} \mathrm{C}$ ). Mixed-gas permeation tests using a binary $1: 1$ $\mathrm{v} / \mathrm{v}$ ethylene/ethane feed under more realistic operating pressures revealed a small performance loss due to a subtle matrix dilation of the selective CMS cavities. Notwithstanding, even the reduced mixed-gas $\mathrm{C}_{2} \mathrm{H}_{4} / \mathrm{C}_{2} \mathrm{H}_{6}$ selectivity of $\sim 16$ measured at 20 bar and $35{ }^{\circ} \mathrm{C}$ is the highest value reported to date for any CMS membrane.

\section{Acknowledgements}

The work reported in this publication was supported by funding from King Abdullah University of Science and Technology (KAUST).

\section{Notes and references}

1 T. Ren, M. Patel and K. Blok, Energy, 2006, 31, 425-451.

2 W. J. Koros, AIChE J., 2004, 50, 2326-2334.

3 J. A. Caballero, I. E. Grossmann, M. Keyvani and E. S. Lenz, Ind. Eng. Chem. Res., 2009, 48, 9151-9162.

4 A. Motelica, O. S. L. Bruinsma, R. Kreiter, M. den Exter and J. F. Vente, Ind. Eng. Chem. Res., 2012, 51, 6977-6986.

5 J. Ploegmakers, A. R. T. Jelsma, A. G. J. van der Ham and K. Nijmeijer, Ind. Eng. Chem. Res., 2013, 52, 6524-6539.

6 R. W. Baker and B. T. Low, Macromolecules, 2014, 47, 69997013.

7 L. M. Robeson, J. Membr. Sci., 2008, 320, 390-400.

8 A. B. Fuertes and I. Menendez, Sep. Purif. Technol., 2002, 28, 29-41.

9 M. Rungta, C. Zhang, W. J. Koros and L. Xu, AIChE J., 2013, 59, 3475-3489.

10 K. Tanaka, A. Taguchi, J. Hao, H. Kita and K. Okamoto, J. Membr. Sci., 1996, 121, 197-207.

11 C. Staudt-Bickel and W. J. Koros, J. Membr. Sci., 2000, 170, 205-214.

12 S. S. Chan, R. Wang, T. S. Chung and Y. Lin, J. Membr. Sci., 2002, 210, 55-64.

13 S. S. Chan, T. S. Chung, Y. Lin and R. Wang, J. Membr. Sci., 2003, 218, 235-245.

14 J. Ploegmakers, S. Japip and K. Nijmeijer, J. Membr. Sci., 2013, 428, 445-453.

15 J. E. Bachman, Z. P. Smith, T. Li, T. Xu and J. R. Long, Nat. Mater., 2016, 15, 845-849.

16 M. Rungta, L. Xu and W. J. Koros, Carbon, 2012, 50, 14881502.

17 K. M. Steel and W. J. Koros, Carbon, 2003, 41, 253-266.

18 A. J. Bird and D. L. Trimm, Carbon, 1983, 21, 177-180.

19 S. M. Saufi and A. F. Ismail, Carbon, 2004, 42, 241-259.

20 L. Shao, T.-S. Chung and K. P. Pramoda, Microporous Mesoporous Mater., 2005, 84, 59-68. 
21 S. Fu, E. S. Sanders, S. S. Kulkarni and W. J. Koros, J. Membr. Sci., 2015, 487, 60-73.

22 M. Inagaki, N. Ohta and Y. Hishiyama, Carbon, 2013, 61, 121.

23 H. B. Park, C. H. Jung, Y. M. Lee, A. J. Hill, S. J. Pas, S. T. Mudie, E. Van Wagner, B. D. Freeman and D. J. Cookson, Science, 2007, 318, 254-258.

24 S. Fu, G. B. Wenz, E. S. Sanders, S. S. Kulkarni, W. Qiu, C. Ma and W. J. Koros, J. Membr. Sci., 2016, 520, 699-711.

25 P. M. Budd, K. J. Msayib, C. E. Tattershall, B. S. Ghanem, K. J. Reynolds, N. B. McKeown and D. Fritsch, J. Membr. Sci., 2005, 251, 263-269.

26 N. Du, H. B. Park, G. P. Robertson, M. M. Dal-Cin, T. Visser, L. Scoles and M. D. Guiver, Nat. Mater., 2011, 10, 372-375.

27 Y. Zhuang, J. G. Seong, Y. S. Do, H. J. Jo, Z. Cui, J. Lee, Y. M. Lee and M. D. Guiver, Macromolecules, 2014, 47, 3254-3262.

28 M. Carta, M. Croad, R. Malpass-Evans, J. C. Jansen, P. Bernardo, G. Clarizia, K. Friess, M. Lanč and N. B. McKeown, Adv. Mater., 2014, 26, 3526-3531.

29 B. S. Ghanem, R. Swaidan, E. Litwiller and I. Pinnau, Adv. Mater., 2014, 26, 3688-3692.

30 B. S. Ghanem, R. Swaidan, X. Ma, E. Litwiller and I. Pinnau, Adv. Mater., 2014, 26, 6696-6700.

31 I. Rose, M. Carta, R. Malpass-Evans, M.-C. Ferrari, P. Bernardo, G. Clarizia, J. C. Jansen and N. B. McKeown, ACS Macro Lett., 2015, 4, 912-915.

32 R. Swaidan, B. Ghanem and I. Pinnau, ACS Macro Lett., 2015, 4, 947-951.

33 P. Li, T. S. Chung and D. R. Paul, J. Membr. Sci., 2013, 432, 50-57.

34 O. Salinas, X. Ma, E. Litwiller and I. Pinnau, J. Membr. Sci., 2016, 504, 133-140.

35 O. Salinas, X. Ma, E. Litwiller and I. Pinnau, J. Membr. Sci., 2016, 500, 115-123.
36 X. Ma, R. Swaidan, B. Teng, H. Tan, O. Salinas, E. Litwiller, Y. Han and I. Pinnau, Carbon, 2013, 62, 88-96.

37 R. Swaidan, X. Ma, E. Litwiller and I. Pinnau, J. Membr. Sci., 2013, 447, 387-394.

38 R. J. Swaidan, X. Ma and I. Pinnau, J. Membr. Sci., 2016, 520, 983-989.

39 S. Li, H. J. Jo, S. H. Han, C. H. Park, S. Kim, P. M. Budd and Y. M. Lee, J. Membr. Sci., 2013, 434, 137-147.

40 X. Ma, O. Salinas, E. Litwiller and I. Pinnau, Polym. Chem., 2014, 5, 6914-6922.

41 H. Shamsipur, B. A. Dawood, P. M. Budd, P. Bernardo, G. Clarizia and J. C. Jansen, Macromolecules, 2014, 47, 5595-5606.

42 J. N. Barsema, S. D. Klijnstra, J. H. Balster, N. F. A. van der Vegt, G. H. Koops and M. Wessling, J. Membr. Sci., 2004, 238, 93-102.

43 X. Ma, R. Swaidan, Y. Belmabkhout, Y. Zhu, E. Litwiller, M. Jouiad, I. Pinnau and Y. Han, Macromolecules, 2012, 45, 3841-3849.

44 Y. Rogan, L. Starannikova, V. Ryzhikh, Y. Yampolskii, P. Bernardo, F. Bazzarelli, J. C. Jansen and N. B. McKeown, Polym. Chem., 2013, 4, 3813-3820.

45 D. G. Pye, H. H. Hoehn and M. Panar, J. Appl. Polym. Sci., 1976, 20, 1921-1931.

46 T. T. Moore, S. Damle, P. J. Williams and W. J. Koros, J. Membr. Sci., 2004, 245, 227-231.

47 K. C. O'Brien, W. J. Koros, T. A. Barbari and E. S. Sanders, J. Membr. Sci., 1986, 29, 229-238.

48 W. R. Vieth, P. M. Tam and A. S. Michaels, J. Colloid Interface Sci., 1966, 22, 360-370.

49 L. Xu, M. Rungta, J. Hessler, W. Qiu, M. Brayden, M. Martinez, G. Barbay and W. J. Koros, Carbon, 2014, 80, 155-166.

50 M. Rungta, Ph.D. thesis, Georgia Institute of Technology, 2012, p. 155. 